
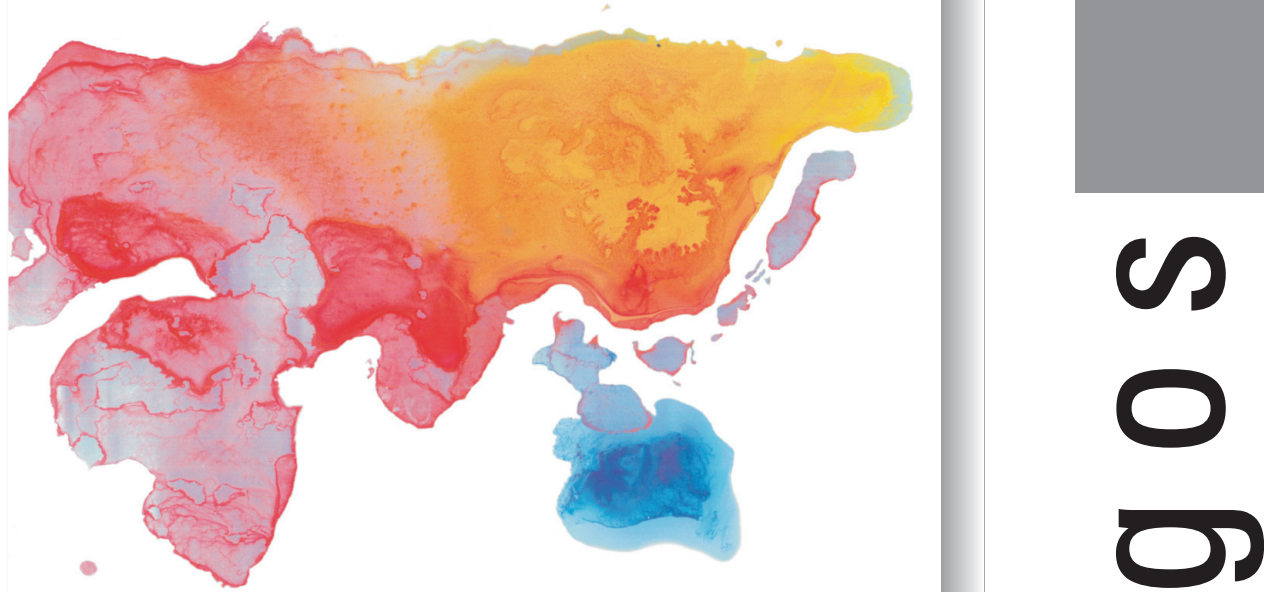

$\square$
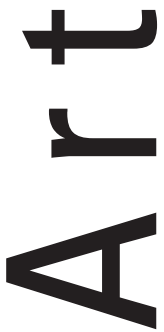


\title{
0 impacto da feira hippie no setor turístico-hoteleiro de Goiânia ${ }^{1}$
}

\author{
El impacto da feira hippie en el sector turístico-hotelero de Goiânia
}

\author{
Gisélia Lima Carvalho - CEFET/GO \\ glc@cefetgo.br \\ Simoni Miriam Wendland - CEFET/GO \\ Wendland10@bol.com.br \\ Ana Maria Guimarães da Mota - CEFET/GO \\ aninhamgm@hotmail.com
}

\section{Resumo}

0 presente artigo é resultado parcial das investigações do projeto "Turismo e Desenvolvimento Socioespacial" que está sendo desenvolvido desde abril de 2006 no Centro Federal de Educação Tecnológica de Goiás - CEFET/GO. As discussões ora apresentadas visam compreender a dinâmica da Feira Hippie de Goiânia e o seu impacto gerado no setor turístico-hoteleiro da cidade de Goiânia. Nos últimos anos, esse empreendimento passou por grandes transformações de ordem social, econômica e espacial que resultaram em alterações nos equipamentos turísticos (sistema de hospedagem e restaurantes, de transportes e agências de viagens) e nos produtos oferecidos. A pertinência desse estudo se dá pelo papel que esta feira representa na configuração do chamado "turismo de compras". Essa problemática serviu de suporte para uma abordagem que resultou na construção de um banco de dados e informações que ajudam na compreensão da dinâmica de parte dos processos turísticos do Estado de Goiás

Palavras-chave: turismo de compras; setor turísticohoteleiro; Feira Hippie de Goiânia

\section{Resumen}

El presente artículo es resultado parcial de las investigaciones del proyecto "Turismo y Desarrollo Socioespacial" que está siendo desarrollado desde abril de 2006 en el Centro Federal de Educación Tecnológico de Goiás - CEFET/GO. Las discusiones aquí presentadas visan comprender la dinámica de la Feria Hippie de Goiânia y el impacto generado en el sector turístico-hotelero de la ciudad de Goiânia. En los últimos años, ese emprendimiento pasó por grandes transformaciones del orden social, económico y espacial que resultaron en alteraciones en los equipamientos turístico (sistema de hospedaje y restaurantes, transportes y agencias de viajes) y en los productos ofrecidos. La pertinencia del llamado "turismo de compras". Esa problemática sirvió de soporte para un abordaje que resultó en construcción de un banco de datos y informaciones que ayudan en la comprensión de la dinámica de parte de los procesos turísticos del Estado de Goiás.

Palabras claves: "turismo de compras"; sector turísticohotelero; Feria Hippie de Goiânia 



\section{Considerações iniciais}

A cidade de Goiânia guarda, nas suas feiras, um grande fator de atratividade turística. Eentre elas está a Feira Hippie de Goiânia que pode ser citada como um patrimônio histórico-cultural e sócio-econômico em virtude do seu valor para a sociedade goianiense. Esta feira gera transformações socioespaciais que atingem, de forma significativa, a região norte do centro de Goiânia e motiva um fluxo contínuo de pessoas em diversas escalas (regional, estadual e interestadual). Esse movimento canaliza divisas para Goiânia, engendra mudanças no padrão e na oferta da hotelaria do entorno que recebe um grande fluxo de ônibus de outras regiões e, por extensão, aumenta o número de galerias e lojas especializadas em confecções. Diante dessa realidade, esse artigo busca compreender a dinâmica do turismo voltado para essa feira, a partir do estudo do seu impacto no desenvolvimento socioespacial. Os focos de análise são: a rede hoteleira, as agências de viagens e os meios de transportes utilizados, os visitantes (turistas) e os vendedores (feirantes). Para tanto, procurou-se responder às seguintes questões: que fatores interferiram no crescimento da Feira Hippie de Goiânia? É possível afirmar que a Feira Hippie estaria modificando o seu entorno, no que diz respeito à hotelaria e às novas empresas de confecção em um território de influência do terminal rodoviário de Goiânia? Como se configura a dinâmica socioespacial dessa feira? ${ }^{2}$

\section{Caracterizando a Feira Hippie de Goiânia}

A Feira Hippie de Goiânia, segundo Dossiê de Goiás (SILVA, 1996), teve início na década de 1970, com a exposição de artesanatos feitos por hippies que se reuniam aos domingos, no espaço onde hoje funciona o Parque Mutirama. Esse grupo foi crescendo e ganhando adesão de outros artesãos que aproveitaram a idéia (op. cit.). Logo depois, para a implantação do Parque Mutirama, a administração municipal mudou os hippies para a Praça Universitária. A transferência não agradou aos vendedores ambulantes, uma vez que a nova localização era de difícil acesso para os consumidores. Assim, "os hippies decidiram chamar a atenção das autoridades e montaram a feira na Praça Cívica, ao lado da prefeitura e do Palácio das Esmeraldas” (op. cit.), no centro da cidade. 
Nesse novo local, a feira passou a adquirir novos integrantes e por lá permaneceu até o final da década de 1970. Quando o espaço já não suportava o grande número de vendedores, as barracas foram sendo montadas ao longo da Avenida Goiás. Nessa altura, a oferta de produtos já estava bastante diversificada, com predomínio de confecções, calçados, alimentos e bens importados do Paraguai que foram servindo como uma nova fonte de renda para os novos feirantes. Em virtude disso, Silva, Pereira e Paula (1999), na sua pesquisa sobre "O Fenômeno da Descaracterização das Feiras Artesanais: o caso da Feira Hippie de Goiânia”, afirmam que

a feira foi aos poucos se descaracterizando, no que se refere ao tipo de produtos comercializados. Houve uma diversificação e passaram a ser, em sua maioria, produtos não-artesanais, como artigos importados, de confecção e alimentação. (p. 11).

Como justificativa para tal fenômeno, as autoras apontam "o aumento populacional da cidade e a demanda dos novos consumidores pela diversificação dos produtos” (Op. Cit). De fato, em relação ao aumento populacional, Goiânia possuía, em 1970, 378.057 habitantes, passando para 714.484, em 1980 e para 989.285 em 1995 (SEPLAN, 1992; 1996), ano de mais uma transferência da feira. Maia e Coelho (1997, p. 10) apontam uma série de fatores para a mudança da Feira Hippie, em 1995, para a Praça do Trabalhador, dentre os quais estão: "o crescimento desordenado" (5.500 expositores e, aproximadamente, 25 mil visitantes); "problemas de segurança para os freqüentadores e expositores"; "dificuldade de controlar como e o que se comercializava na feira" e "conturbações no trânsito do centro da cidade e na vida de seus moradores".

Nesse novo local, presume-se que a Feira Hippie de Goiânia foi mais bem planejada socio-espacialmente. No entanto, a percepção que tivemos é que esse espaço ainda representa, para a SEDEM (Secretaria de Desenvolvimento Municipal), um desafio ao planejamento, uma incógnita, sobretudo pela ausência de dados sobre a sua real dimensão. A feira aumenta a cada semana e, por isso, é entendida como sinônimo de problema, pelo governo municipal, o que motiva debates constantes sobre outras mudanças espaciais e medidas de controle organizacional.

Atualmente, a Feira Hippie, segundo dados fornecidos pela Associação da Feira Hippie de Goiânia, possui cerca de 10 mil expositores (sendo que destes, 4 mil estão em situação irregular com a Prefeitura e a SEDEM). Diante disso, e de sua relevância para a sustentabilidade da economia de 
muitas famílias, essa feira passou a ser conhecida como a "maior feira da América Latina”.

Durante o trabalho de campo, observamos com mais detalhe a rotina da feira com o fito de compreender sua dinâmica organizacional. Segundo a Presidente da Associação, sua montagem é iniciada às $2 \mathrm{~h}$ madrugada de domingo e permanece na praça até às $14 \mathrm{~h}$. No entanto, foi possível observar que esses prazos se antecedem: a montagem é iniciada na tarde de sábado e as vendas começam a ser feitas na mesma noite, estendendo-se até o final da tarde de domingo. Além disso, uma nova imagem pode ser vista no espaço da Praça do Trabalhador: durante a semana, alguns feirantes estendem suas bancas em uma rotina aparentemente normal e permanecem até a chegada do final de semana. Essa realidade toma uma nova dimensão, gerando um grande fluxo de pessoas, naqueles domingos que antecedem feriados e principalmente no mês de dezembro, quando o movimento atinge seu ápice, chegando a mais de 50 mil visitantes, segundo informações da Associação. Esse dado foi confirmado na pesquisa dos meios de hospedagem do Setor Norte Ferroviário e das agências de viagens do setor.

\section{Produtos oferecidos e pessoal ocupado}

Quanto à oferta dos seus produtos, a Feira Hippie de Goiânia continua diversificada, ao mesmo tempo em que confirma a sua tendência para as confecções (figura 01).

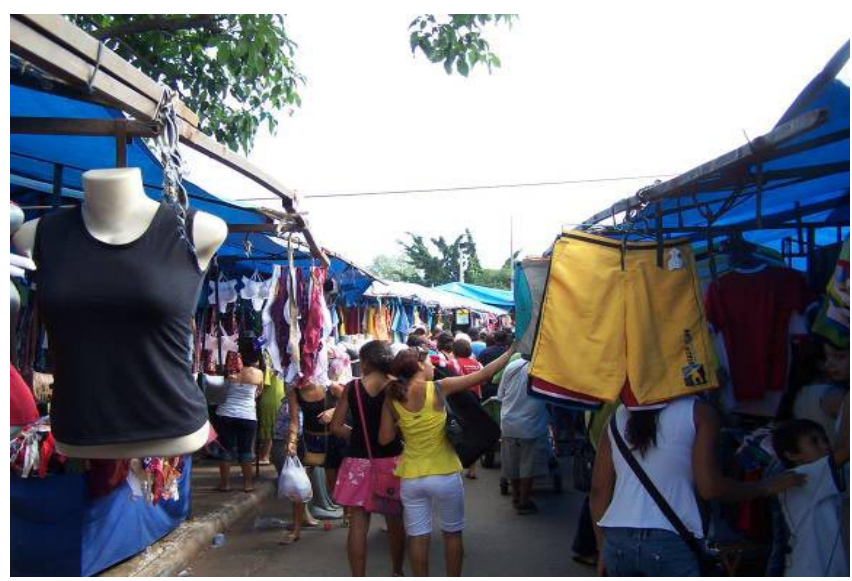




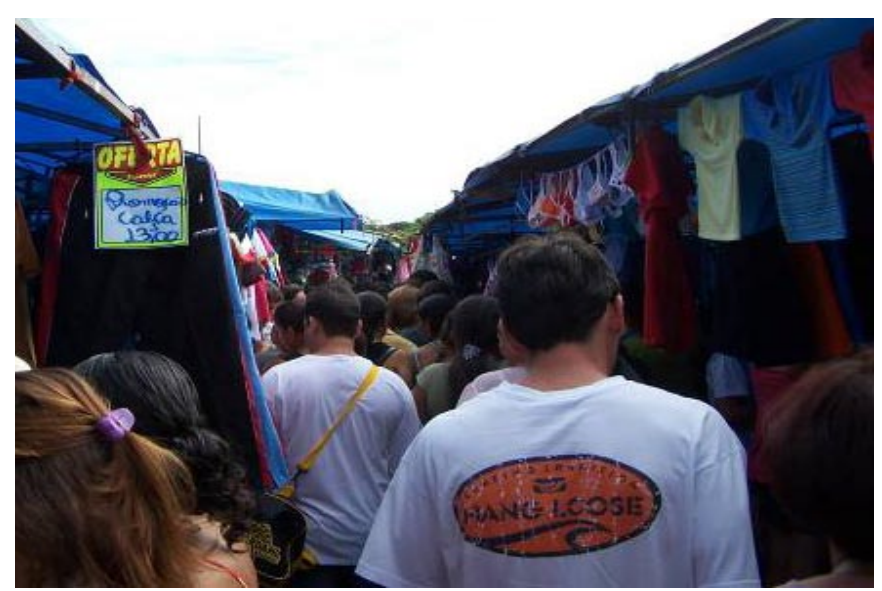

Figura 01: Fluxo de visitantes na Feira Hippie de Goiânia; tendência para o setor de confecções. Fotos: CARVALHO, G. L. (dezembro de 2006)

Segundo dados da pesquisa, comprovamos que o setor de confecções é o de maior destaque dentre os produtos comercializados na feira. Dos 170 feirantes entrevistados, 53\% têm sua renda através da venda de artigos de confecção, 20\% de artesanato, 14\% de outros produtos (alimentos, moda praia, bijuterias, pedras, esculturas, revistas, cintos e tapetes), $10 \%$ de calçados e $3 \%$ de bolsas.

Constatamos que a empregabilidade da feira é, sobretudo, de origem familiar. Dos entrevistados, $86 \%$ dos que trabalham nas bancas são da família do proprietário, 9\% têm somente empregado não-familiar e $5 \%$ têm familiares e outros empregados. Do total, $60 \%$ têm posto de trabalho somente na Feira Hippie e os demais, $40 \%$, também vendem seus produtos em outros lugares.

Chama a atenção o fato da capacidade que esta feira tem de gerar empregos. Conforme dados da Associação da Feira Hippie de Goiânia, ela gera aproximadamente 10 mil empregos diretos e 40 mil indiretos. E isto não é espantoso quando apresentamos os resultados do gráfico abaixo. Dos feirantes entrevistados, 58\% possuem 2 pessoas trabalhando na banca; $32 \%$ possuem 1 pessoa; $8 \%$ possuem 3 pessoas e os demais, 2\%, possuem 4 pessoas ou mais (figura 02).

Quanto ao tempo que os entrevistados trabalham na feira, $26 \%$ responderam ser acima de 10 anos $^{2} ; 22 \%$, há 10 anos; 21\%, há 5 anos; $17 \%$, há 3 anos e, os demais, 13\%, há 1 ano. A partir desses dados, podemos inferir quão estabelecidas estão as relações entre o feirante e a Feira Hippie. 
Pessoas que trabalham na Feira Hippie de Goiânia, por banca

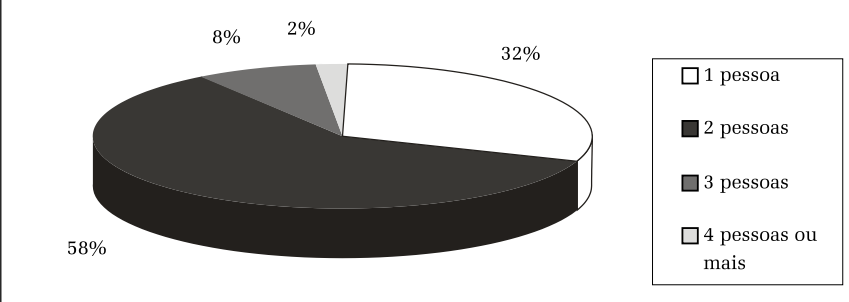

Figura 02. Fonte: Pesquisa de campo, 2006-2007

Em relação à origem dos produtos comercializados na feira, 86\% responderam que são fabricados na cidade de Goiânia. Do restante, 8\% vêm de outros municípios do Estado de Goiás e 6\% de outros Estados brasileiros (figura 03). Esse dado é um forte indicador de sua importância econômica, especialmente no que se refere ao valor agregado, uma vez que produção, geração de emprego e circulação estão concentrados em Goiânia. Outro ponto interessante diz respeito à empresa de caráter familiar. Do total de entrevistas, obtivemos o seguinte resultado: $82 \%$ dos produtos vendidos são de fabricação própria e somente $18 \%$ a terceirizam (figura 04). A partir dos dados, percebe-se que a maioria dos vendedores fabrica os seus próprios produtos em Goiânia somente para atender à Feira Hippie, o que corrobora com os números sobre empregos diretos e indiretos.

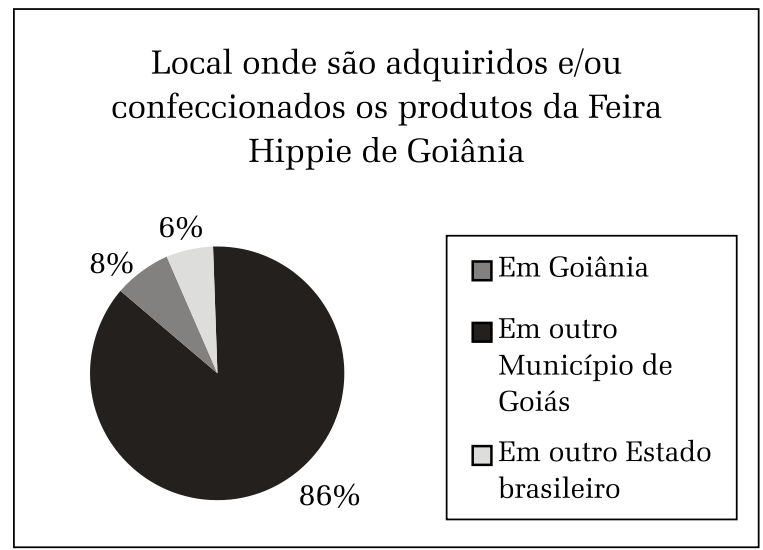

Figura 03. Fonte: Pesquisa de campo, 2006-2007 
Tipo de fabricação dos produtos da Feira

Hippie de Goiânia

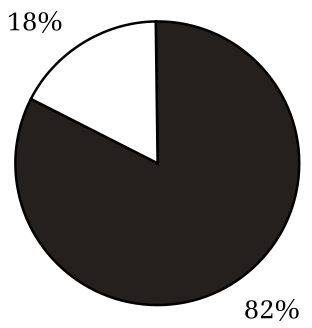

$\square$ Própria

Terceirizada

Figura 04. Fonte: Pesquisa de campo, 2006-2007

Em relação ao mercado consumidor desses produtos, a pesquisa demonstrou ser, majoritariamente, composto por mulheres (80\%), o que nos lembra o conceito "terciário refúgio", caracterizado por Santos (1979) como um "elemento fundamental da vida urbana nos países subdesenvolvidos" ( $\mathrm{p}$. 158), cuja alternativa de geração de emprego e renda para as famílias se dá via inserção das mulheres no mercado, sobremaneira no setor de serviços.

\section{0 setor turístico-hoteleiro}

Na pesquisa, comprovamos que já havia um tímido crescimento na hotelaria e, sobretudo, das agências de viagens que antecede ao surgimento da Feira Hippie de Goiânia no Setor Norte Ferroviário (em 1995). Isto é justificável devido ao grau de influência que os terminais rodoviários exercem nas cidades. Contudo, notamos que esse crescimento se intensificou a partir de 1996, ano seguinte a instalação da feira. Dos 27 meios de hospedagem pesquisados ( $75 \%$ do total do setor), somente 07 foram construídos entre os anos de 1961 e 1995. Os demais, 20 meios de hospedagem (74\%), foram instalados depois da chegada da feira ${ }^{4}$ - ver diversificação da hotelaria do setor (figura 05). 

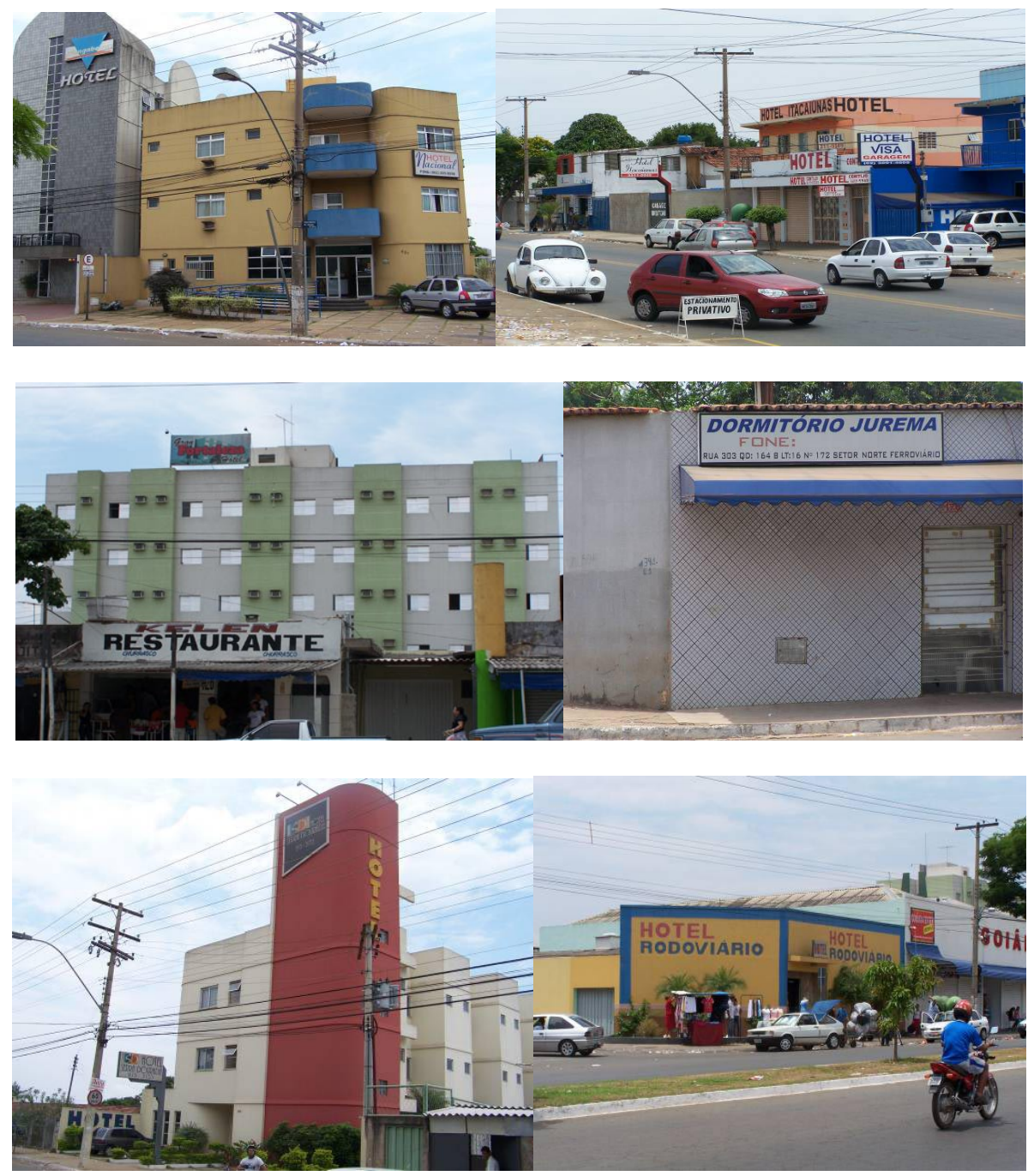

Figura 05: Meios de Hospedagem do Setor Norte Ferroviário de Goiânia. Fotos: CARVALHO, G. L. (agosto de 2006)

Das 33 agências pesquisadas, 31 (94\%) passaram a existir depois da chegada da feira no setor ${ }^{5}$. Esses dados explicam a importância da Feira Hippie já que foi lembrada como sendo o principal fator de influência na localização dos seus respectivos estabelecimentos. O terminal rodoviário foi 
citado como o segundo fator e, logo depois, o comércio do entorno da feira e da Avenida Bernardo Sayão, respectivamente (figura 06).

Fatores que influenciaram a localização dos Meios de Hospedagem do Setor Norte Ferroviário (grau de influência de 0-10)

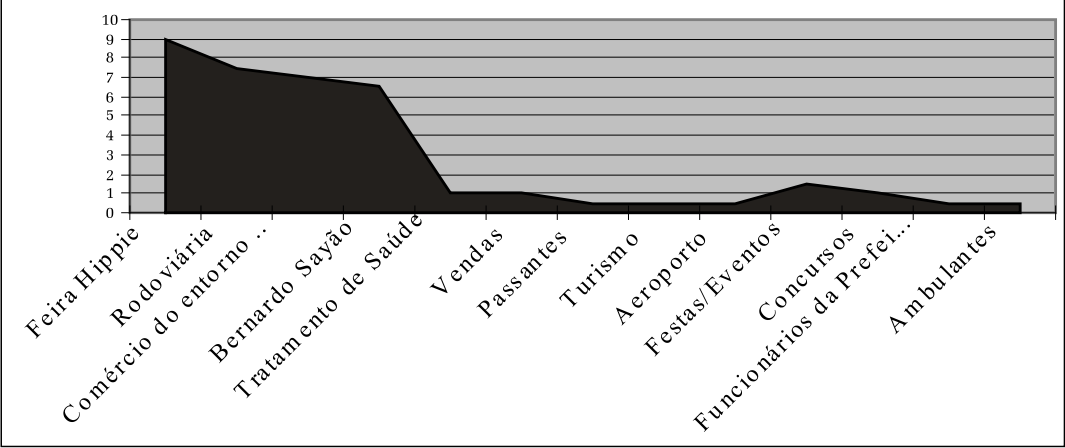

Figura 06. Fonte: Pesquisa de campo, 2006-2007

Também verificamos o grau de atratividade do setor de compras para a hotelaria e as agências de viagens. Para os dois setores, as compras, de confecções, sobretudo, são o maior incentivo à entrada de turistas na cidade de Goiânia. Conforme os representantes da hotelaria do entorno, seus hóspedes são procedentes de vários Estados brasileiros, com destaque para Pará, Tocantins, Rondônia, Maranhão, Minas Gerais e São Paulo. Desses visitantes, $47 \%$ têm no turismo de compras sua principal motivação, 20\% na saúde e os demais, 33\%, noutras motivações (lazer, eventos e negócios). O período de maior fluxo dos visitantes nos estabelecimentos hoteleiros corresponde aos finais de ano, mas, segundo entrevistas, mantém-se equilibrado o ano todo, garantindo sustentabilidade para o setor. Em relação ao fluxo semanal, ele se dá durante toda a semana, mas começa a crescer a partir de quinta feira, concentrando-se entre sexta e domingo. (figura 07) .

A figura ao lado dá a idéia da expansão do impacto do movimento da feira na economia goiana. Mesmo sendo um rotina dominical apenas, ela tem sido capaz de estimular a permanência dos seus visitantes na cidade, ocorrendo um processo de transformação de um visitante em um agente que gera divisa e, por conseqüência, movimenta a cadeia do turismo, tornandose "turista". (figura 08). 


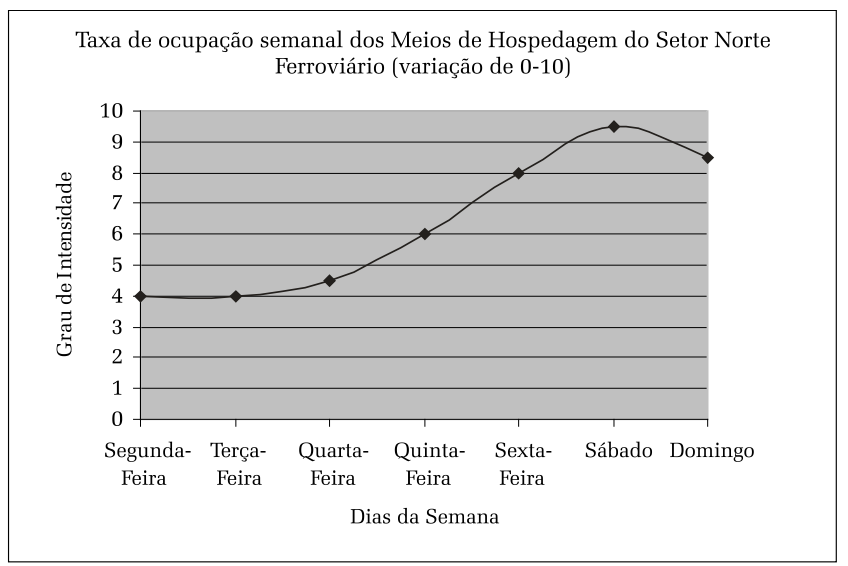

Figura 07. Fonte: Pesquisa de campo, 2006-2007

\begin{tabular}{|l|c|c|}
\hline \multicolumn{1}{|c|}{ Permanência em Goiânia (em dias) } & $\mathrm{N}^{\mathrm{o}}$ de entrevistados & Porcentagem \\
\hline Day Use (menos de um dia) & 0 & $0 \%$ \\
\hline 1 dia & 36 & $18 \%$ \\
\hline 2 dias & 32 & $16 \%$ \\
\hline 3 dias & 80 & $40 \%$ \\
\hline 4 dias & 12 & $6 \%$ \\
\hline Acima de 4 dias & 40 & $20 \%$ \\
\hline Total de visitantes & 200 & $100 \%$ \\
\hline
\end{tabular}

Figura 08: Índice de permanência em Goiânia dos visitantes da Feira Hippie de Goiânia

O quadro acima merece atenção especial haja vista que a esta feira sempre foi atribuída a falsa idéia de que o seu visitante não dorme na cidade, não gerando um impacto significativo para a economia de cidade, ocorrendo o que se entende por day-use . $^{6}$

Um pilar importante desse processo é constituído pelas agências de viagens do setor. Das 42 agências de viagens do Setor Norte Ferroviário (75,5\% do total) foram entrevistadas 33 . A partir dos dados adquiridos, chegamos a um cálculo superior a 5.000 passagens por semana, o que equivale, supostamente, a uma média de 156 por agência. Essa média é plenamente coerente, uma vez que as agências têm a sua disposição um total de 237 ônibus, o que corresponde a um trânsito de sete ônibus por agência durante 
a semana. Do total, 94\% é especializada em roteiros únicos e somente $6 \%$ oferece alternativas, conforme exigência dos clientes (figura 09).

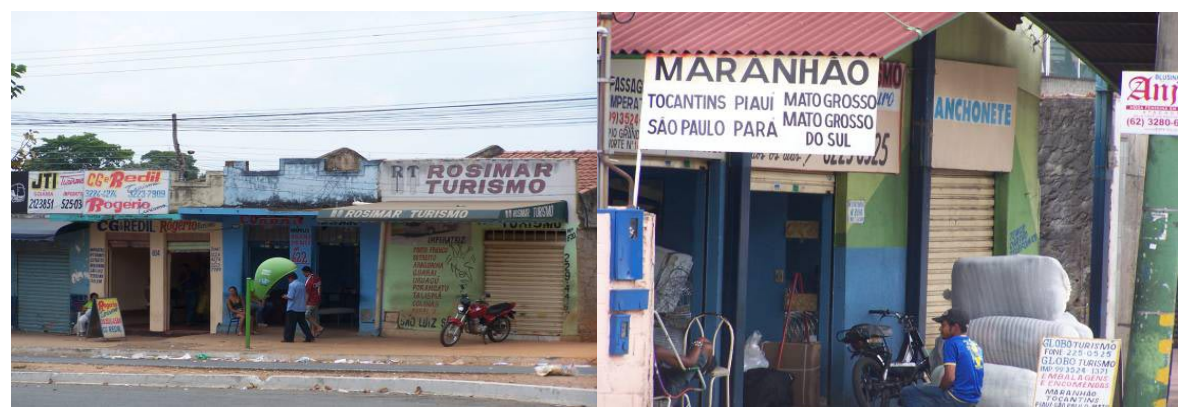

Figura 09: Perfil de algumas Agências de Viagem do setor Norte Ferroviário. Fotos: CARVALHO, G. L. (Novembro de 2006)

Apesar da sua relevância para o turismo, 82\% das agências entrevistadas não possuem registro na ABAV (Associação Brasileira de Agências de Viagens) ou na EMBRATUR (Instituto Brasileiro de Turismo). Suas atividades atendem a uma dinâmica que vai além da motivação para os negócios que lhes permitem garantir valores de passagens até 50\% inferiores às empresas oficiais, localizadas na rodoviária. Isso é incrementado pela demanda real da clientela que foi se constituindo em Goiânia, nos últimos anos, em relação à migração de tocantinenses e maranhenses, sobretudo as que vêm buscar melhores condições de vida e sempre retornam, mantendo os laços de afetividade familiar. Como boa parte dessa clientela se faz de jovens assalariados, a opção por uma passagem de valor inferior àquela da rodoviária se configura como a melhor alternativa. Com a oferta acentuada, os turistas podem vir a Goiânia com relativa freqüência. Diferente da hotelaria do setor, $55 \%$ das agências possuem em seu quadro de funcionários relações contratuais; em 33\%, empregados e familiares e 12\% delas se mantêm só com familiares.

Para os visitantes da feira, foi aplicado um total de 200 questionários. Quarenta e oito por cento (48\%) vêm à Goiânia mensalmente; $26 \%$, quinzenalmente; $12 \%$, anualmente ou muito raramente; $8 \%$ vêm a cada 2 ou 3 meses e os demais, 6\%, vêm semanalmente. Do total, 78\% se hospedam nos hotéis e dormitórios e 89\% só realizam compras em Goiânia, sendo que 11\% o fazem também em outros Estados. Quanto ao gasto médio de compras em Goiânia, $82 \%$ afirmaram ser de até 1.000 reais; $11 \%$ de até 2.000 reais e os 
demais, 7\%, chegam a gastar até 5.000 reais. Quanto à procedência desses entrevistados, 39\% são de Goiânia; 34\% de outros Estados e 25\% de municípios goianos.

Um fator preponderante para a conceituação técnica do turismo é o das "divisas" pacidade de importar capitais para um determinado núcleo receptor. Nas palavras do economista belga Von Schullard (apud, ANDRADE, 1998, p. 33), a importância dessas divisas reside no impacto que os gastos dos turistas "podem trazer para os diferentes setores da economia". Como a renda turística é composta de atividades e ramos estrito e indiretamente turísticos, podemos dizer que, nesse caso, a oferta de produtos provenientes da feira é um elemento a mais na geração de receita turística.

\section{A criação de novos espaços para compras motivados pelo turismo}

Ao pensarmos na referida feira e no seu impacto no Setor Norte Ferroviário de Goiânia, somos remetidos a um conceito de turismo bastante geral, elaborado por Barreto (2000), a partir de uma visão que dimensiona a atual pertinência de um movimento, sobretudo sociológico, gerado pela categoria mobilidade. O turismo pode ser compreendido como um fenômeno que gera "múltiplas inter-relações de importância social, econômica e cultural" (LA TORRE, 1992, apud. BARRETO, 2000, p. 13). Este conceito amparou a pesquisa, haja vista que não dá para negar a relevância das inter-relações das diferentes ordens, que se configuram e comungam no território da Feira Hippie de Goiânia. É fato inegável que o tipo de fluxo com destino a ela não está associado a uma atividade de lazer, mas de trabalho (o que não invalida um possível conceito de turismo ${ }^{08}$ ). Nesse caso, dentro da variada gama de tipologias, podemos ressaltar que a tipificação "turismo de negócios" referencia essa análise. Isto porque ela diz respeito ao:

Conjunto de atividades de viagem, de hospedagem, de alimentação e de lazer praticado por quem viaja a negócios referentes aos diversos setores da atividade comercial ou industrial para conhecer mercados, estabelecer contatos, firmar convênios, treinar novas tecnologias, vender ou comprar bens ou serviços (ANDRADE, 1998, 73-74). (grifo nosso).

Segundo Andrade (1998), no Brasil, nos últimos tempos, tem crescido muito esse tipo de viagens dirigidas a centros produtivos, a zonas comerciais 
francas e a regiões fronteiriças, tanto para compras de bens para uso pessoal como para destinação comercial. Para o autor, tais viagens, por serem "movidas pelo lucro e pela comercialização, organizadas por agências ou não, individuais ou coletivas”, contemplam melhor a sua motivação com o termo "turismo de compras" ou "viagens de compras" 09 . Todavia, elas continuam sendo consideradas, segundo o autor, como "turismo de negócios" que, de acordo com a Organização das Nações Unidas (ONU) devem ser classificadas como "turísticas" (p. 74). Entendemos que não poderia ser diferente, visto que essas viagens profissionais têm o poder de movimentar economias, gerar divisas, utilizando equipamentos e serviços turísticos, e fazendo um jogo intrincado de relações com a localidade receptora, sendo capaz de reordenar os seus espaços, adequando-se às demandas do público freqüentador.

Nas entrevistas com os freqüentadores da feira, percebemos que a motivação do deslocamento para a feira está no “turismo de compras” para 85\% deles; para 11\% está nas compras e no lazer; para 2\%, nas compras e na saúde; para 1\%, nas compras e nos eventos e 1\% noutras motivações (Figura 10). Esse dado reafirma a importância das compras, mas revela que $15 \%$ desses freqüentadores aproveitam outras vantagens oferecidas pela cidade, o que reforça ainda mais a importância da feira como estimuladora de outras modalidades de turismo para Goiânia.

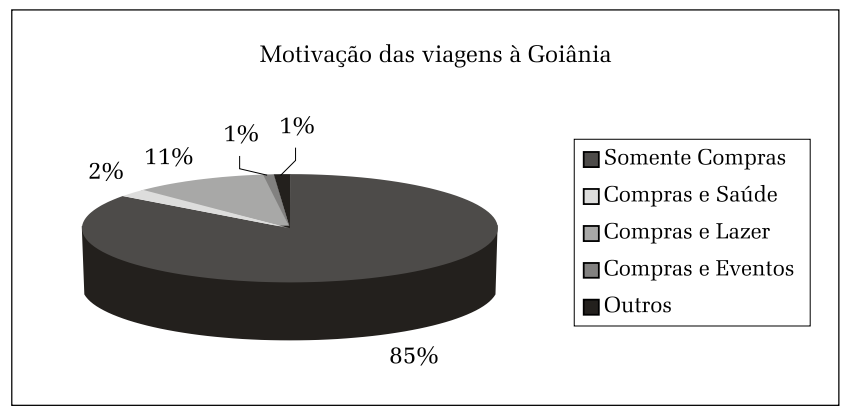

Figura 10. Fonte: Pesquisa de campo, 2006-2007

É comum encontrarmos a afirmação de que o Estado de Goiás se tornou "um pólo regional de confecções, apresentando um quadro muito favorável no contexto nacional” isto é: "das 13 mil empresas ligadas ao setor existentes no Brasil, 4 mil estão localizadas em Goiás, sendo que 60\% delas estão situadas em Goiânia” (SEPLAN/GO, 2000, p. 45). A pulverização de lojas, galerias (destaque para as do setor Norte ferroviário - figura 11) e fei- 
ras (Feira de Lua, a Feira do Sol), que vendem roupas em Goiânia, estimula a melhoria da qualidade e da diversidade dos produtos a partir da pressão espaços concorrentes.
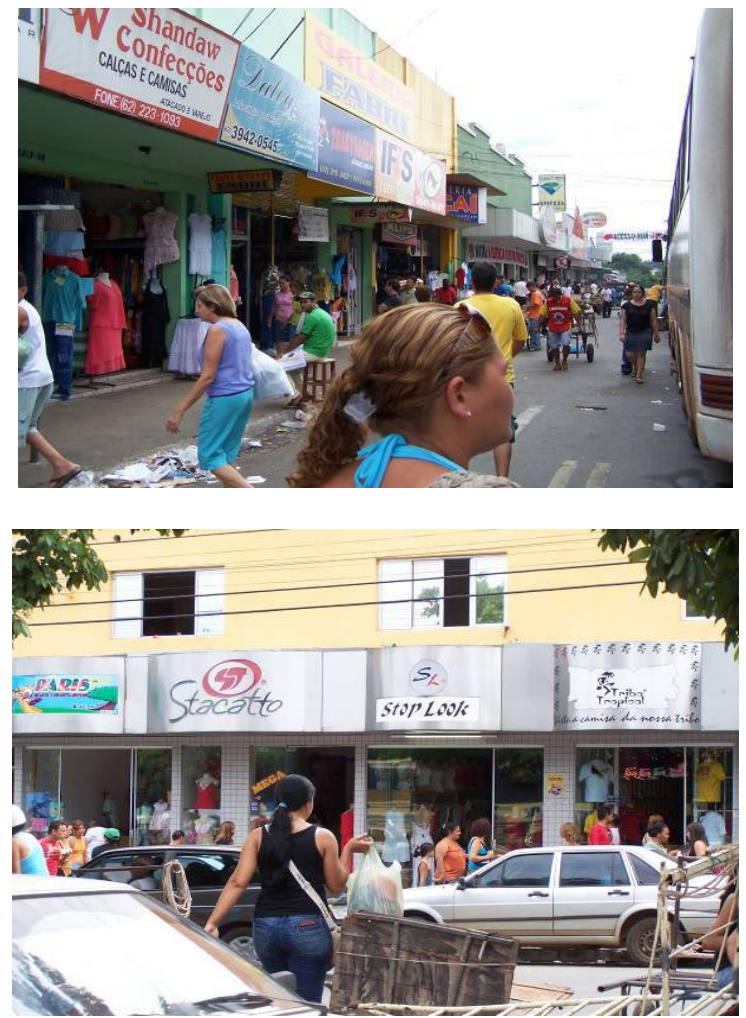

Figura 11: Dia de domingo nas galerias e lojas do entorno da Feira Hippie de Goiânia. Fotos: CARVALHO, G. L. (dezembro de 2006)

Em relação às galerias e lojas do entorno da Feira Hippie, não há dúvida de que são espaços criados a partir do desempenho do papel da Feira Hippie no setor de confecções, cuja referência se fez, na opinião dos consumidores, devido à "boa qualidade" e aos "preços acessíveis". Assim, esses espaços de confecções vendem peças com padrão semelhante ao da feira e se aproveitam de toda a estrutura já criada no setor, atendendo aos gostos de um comprador que já está acostumado a uma rede de serviços oferecidos pela feira. Podemos deduzir que este também é o caso da Estação Goiânia ${ }^{10}$, um novo espaço para realização de feiras e eventos na região que, segundo 
preocupações de alguns feirantes, “irá desbancar a Feira Hippie” porque está sendo organizada para não resvalar nos problemas atuais que a mesma enfrenta. Parte desses problemas foram citados na pesquisa: dos turistas entrevistados, 68\%, consideram “a Feira Hippie perigosa”, já que ocorrem assaltos com freqüência. Além disso, a maioria ainda comenta sobre a "desorganização das bancas”, “a falta de espaço nos corredores” devido ao aumento de bancas clandestinas, "ao excesso de carrinhos de ambulantes passando entre os consumidores", "à sujeira causada nos dias de chuva”, entre outros pontos a seu desfavor. Contudo, não deixam de ressaltar "o bom preço encontrado nas mercadorias", "o bom atendimento da maioria dos vendedores", "a quantidade e diversidade de produtos oferecidos" e ainda, o fato de a Feira Hippie estar situada em "um local de fácil acesso"11, tanto para pessoas que chegam de ônibus através da rodoviária, quanto para as demais.

\section{O debate da transferência da Feira Hippie de Goiânia}

No ano de 2006, a discussão do debate da transferência da Feira Hippie tomou fôlego com o processo de criação da Estação Goiânia. Esse espaço concorrerá com a Feira Hippie, assim como levará alguns de seus permissionários. O depoimento de duas vendedoras do setor de confecções da feira hippie revela a opção pelo novo e "seguro" empreendimento: "Hoje, a gente precisa da Feira Hippie, mas estamos muito inseguras com ela, pois não sabemos se vai acabar. A Estação vai ser um shopping mais aconchegante para os compradores e turistas"(www.estacaogoiania.com).

Independente da existência de um projeto de transferência da Feira Hippie da Praça do Trabalhador para a Estação Goiânia, a maioria dos feirantes e turistas não a aprova, assim como os demais setores ligados à hotelaria e às agências de viagens, pois vêem que o público irá mudar. Ou seja, como o custo para os feirantes e turistas será mais elevado, também haverá uma exigência maior para que os hotéis e agências tenham melhores condições e estejam devidamente registrados. Para todos os agentes pesquisados, a feira é entendida como sinônimo de vendas, lucratividade e outros benefícios. Para darmos a real idéia desse fato, dos 177 feirantes entrevistados, 93\% não gostariam que a Feira Hippie fosse transferida para a Estação Goiânia e, para a mesma pergunta feita aos turistas (consumidores) 63\% deram a mesma resposta. Nota-se, então, que a vontade considerável da maioria é de que a feira permaneça no seu local atual. 
Para reiterar tal interesse, ressaltamos a contribuição que tivemos dos diversos entrevistados. Por exemplo, no segmento dos meios de hospedagem, dos hotéis visitados, a totalidade dos entrevistados respondeu que a fundação dos seus hotéis se deveu, principalmente, à existência da Feira Hippie de Goiânia na região, como destacado anteriormente. O pessoal da hotelaria concorda com as agências do setor quando trata sobre a importância das vendas que a feira promove. Isto se configura como um fato porque o mesmo público que é recebido pelos feirantes, permanece na cidade por, pelo menos, 24 horas, o que acarreta lucros para todos os elementos que compõem o sistema turístico.

\section{Considerações finais}

A pesquisa que deu origem a esse artigo se propôs a discutir questões referentes aos fatores que influenciam no crescimento da Feira Hippie de Goiânia e na modificação do seu entorno e dos equipamentos turísticos que surgiram ao longo do tempo no Setor Norte Ferroviário, com destaque para as proximidades do Terminal Rodoviário de Goiânia. Ficou comprovada a importância desse espaço como um atrativo turístico sólido que gera desenvolvimento econômico e reflete na reconfiguração espacial daquele setor, a partir do crescimento de novos espaços de confecções, da expansão da rede hoteleira, do aumento do número de agências de viagens no seu entorno e da criação de um número expressivo de empregos diretos e indiretos. Além disso, é reconhecido pelos entrevistados (feirantes e turistas-consumidores) o seu valor de patrimônio histórico-cultural para a cidade e que, em virtude disso, precisa ser assumida pelo poder público no sentido de que o mesmo tome as medidas necessárias para a melhoria dos seus equipamentos, da segurança e da manutenção da identidade e da memória desse espaço. Isto foi confirmado a partir da opinião de $95 \%$ dos feirantes que a consideram de alto valor histórico e turístico para a cidade. Em função disso, a maioria dos feirantes e visitantes não aprova mais uma transferência da Feira Hippie para outro espaço, apesar de os últimos lhe atribuírem problemas de ordem estrutural e organizacional.

Os elementos enfocados no decorrer da pesquisa dão subsídio para os estudiosos e gestores do turismo goiano no sentido de colocar a Feira Hippie e toda a rede estrutural que a cerca como um atrativo sólido para o conceito de "turismo de negócios", na sua modalidade "compras". Essa 
tipologia resguarda uma grande vantagem em relação ao turismo de lazer, especialmente porque, segundo Moletta (2002), distribui melhor o fluxo de demanda durante todo o ano, aumenta a articulação com outros setores da produção (primário, secundário e terciário) e, assim como os demais tipos de turismo, gera empregos, melhora a qualificação da mão-de-obra, gera divisas e impostos. Desse modo, a Feira Hippie se configura como um importante nicho da atividade econômica em virtude da sua tendência de crescimento, movimentando toda uma cadeia produtiva e gerando um grande impacto na economia local, caminhando para alcançar o que Souza (2002) denomina de "desenvolvimento socioespacial".

Como forma de lançar temas para possíveis discussões, queremos pontuar algumas teses que insistiram em desvelar-se ao longo desse artigo: 1) a hotelaria do setor (simples e econômica) que cerca a Feira Hippie de Goiânia é um reflexo da economia urbana que se dá de forma diferencial atendendo, como define Santos (1979), aos seus diferentes "circuitos"; 2) existe uma simbiose entre os meios de hospedagem, os transportes e o setor de compras, formando um sistema turístico; 3) atribui-se a Goiânia um grande potencial para o turismo de compras de confecções em atacado, consagrando-se como estimuladora da entrada de divisas devido a sua centralidade e a seus "arranjos produtivos locais” (APLs). Esse potencial antecede à imagem da cidade de Goiânia como uma das capitais dos eventos e negócios no Brasil. Assim, essa cidade desponta como uma importante capital do "turismo de compras" no Brasil.

\section{Notas}

1 Artigo resultante de Projeto de Iniciação à Pesquisa da Coordenação de Turismo de Hospitalidade do Centro Federal de Educação Tecnológica de Goiás - CEFET/GO, orientado pela Profa. Gisélia Lima Carvalho.

2 A pesquisa que originou este artigo é de cunho teórico-empírico e foi realizada entre os meses de abril de 2006 e março de 2007, com o apoio do Programa de Bolsas de Iniciação à Pesquisa (PIBIC), do Centro Federal de Educação Tecnológica de Goiás (CEFET-GO). A parte empírica, posta em maior ênfase aqui, foi sendo construída a partir de quatro roteiros de entrevistas, com perguntas diretas e indiretas, para os grupos específicos de usuários. Ao longo de quatro meses, foram aplicados 430 questionários, assim divididos: 27 para o setor hoteleiro, 33 para as agências de viagens, 200 para freqüentadores-turistas (compradores dos produtos da feira) e 170 para os feirantes.

3 Deduzimos que esse grupo de feirantes já fazia parte da feira quando esta se situava na Av. Goiás.

4 Dos meios de hospedagem visitados no setor, 89\% são hotéis de categoria simples e econô- 
mica e os outros são dormitórios.

5 Diferente da hotelaria do setor, a primeira agência só aparece 30 anos depois, em 1991, segundo as entrevistas.

6 O conceito de day use foi um dos itens na pergunta sobre o tempo de permanência dos visitantes na cidade de Goiânia. O interessante é que achávamos que haveria um número significativo para ele. Resultado: nenhum deles respondeu esse item.

7 Conceito de "Divisa" refere-se ao fato de que através do turismo receptivo, aumentaria a disposição de capitais para a localidade receptora advindos de outras localidades, somando divisas para a primeira. É uma entrada direta de capitais que, muitas vezes, os governos e os empresários locais não precisam investir tanto para atraí-los.

8 No geral, ao conceito de turismo associa-se uma idéia de lazer. Todavia, sabemos que muitas outras motivações estão atreladas às viagens como a religião, os negócios, a saúde, etc.

9 Andrade (1998) alerta para que não confundamos as compras de produtos turísticos (souvenirs) como turismo de negócios. Comprar souvenirs é uma atitude que está presente em quase toda modalidade de turismo. Trazendo para o nosso exemplo, pessoas que vêm visitar Goiânia por algum motivo qualquer, são ligeiramente convencidas de conhecer as feiras típicas de Goiânia, como a Feira Hippie, a da Lua e a do Sol. Isso não se caracteriza como Turismo de Negócios e difere bastante do fluxo de pessoas que vem até Goiânia único e exclusivamente comprar em atacado para revender, configurando a adjetivação de "sacoleiras".

10 Diz o folder de propaganda da Estação Goiânia que "aos sábados e domingos, já está garantida a realização da maior feira coberta da América Latina" que será também "sede de shows, congressos, exposições e outros eventos simultâneos durante sete dias na semana". (www. estacaogoiania.com)

11 Além da centralidade da Feira Hippie na cidade de Goiânia, outro fator locacional favorece a cidade já que está situada na região central do país com fácil acesso para todas as regiões brasileiras. Arrais (2004), considerando esse elemento, aponta Goiânia como parte fundamental de "teia de relações com outras cidades e Estados, formando a chamada 'rede urbana".

\section{Referências}

ANDRADE, José Vicente de. Turismo: dimensões e fundamentos. São Paulo: Ática, 1998.

ARRAIS, Tadeu P. A. Geografia Contemporânea de Goiás. Vieira: Goiânia, 2004.

BARRETO, Margarida. Iniciação ao estudo do turismo. São Paulo: Papirus, 2000.

CARVALHO, Gisélia Lima; MOTA, Ana Maria Guimarães da; WENDLAND, Simoni Miriam. Turismo e desenvolvimento socioespacial: o impacto da Feira Hippie no setor turístico-hoteleiro de Goiânia. (Relatório de Pesquisa). PBIC. Goiânia: CEFET-GO, 2007.

COELHO, Tito O. O comércio varejista periódico no espaço urbano contemporâneo: um estudo na Feira Hippie de Goiânia (Monografia de Bacharelado). IESA-UFG: Goiânia, 1996.

MOLETTA, Vânia Florentino. Turismo de Compras. Porto Alegre: SEBRE/RZ, 2000.

SANTOS, Milton. O espaço dividido: os dois circuitos da economia urbana dos países subdesenvolvidos. Rio de Janeiro: F. Alves, 1979.

SEPLAN. Anuário Estatístico do Estado de Goiás, Goiânia, 1992. 
. Anuário Estatístico do Estado de Goiás, Goiânia, 1996.

2000 .

- Revista Economia e Desenvolvimento. Goiânia: Ano 1, $\mathrm{n}^{\circ}$ 4, julho/setembro de

SILVA, Andréia P., PEREIRA, Azenaide L. \& PAULA, Flavia $\mathrm{M}^{\mathrm{a}}$ de A. O fenômeno de descaracterização das feiras artesanais: o caso da Feira Hippie de Goiânia. Relatório de Projeto. IESAUFG: Goiânia, 1999.

SOUZA, Marcelo Lopes de. Como pode o turismo contribuir para o desenvolvimento local? In: RODRIGUES, Adyr, Balasteri. (Org.). Turismo e desenvolvimento local. São Paulo: Hucitec, 2002 p.17-22.

www.estacaogoiania.com

Gisélia Lima Carvalho - Orientadora da pesquisa e Professora da Coordenação de Turismo e Hospitalidade do CEFET/GO

Simoni Miriam Wendland - Orientadora da pesquisa e Professora da Coordenação de Turismo e Hospitalidade do CEFET/GO

Ana Maria Guimarães da Mota - Voluntária do projeto e aluna do Curso de Tecnologia em Gestão Hoteleira do CEFET/GO.

Recebido para publicação em setembro de 2007

Aceito pra publicação em novembro de 2007 